\title{
Exploring Peirce's speculative grammar: The immediate object of a sign
}

\author{
Francesco Bellucci \\ Department of Philosophy, Tallinn University of Technology \\ Ehitajate tee 5, 19086 Tallinn, Estonia \\ e-mail: bellucci.francesco@gmail.com
}

\begin{abstract}
The paper argues against what I call the "Fregean interpretation" of Peirce's distinction between the immediate and the dynamic object of a sign, according to which Peirce's dynamic object is akin to Frege's Bedeutung, while Peirce's immediate object is akin to Frege's Sinn. After having exposed the Fregean interpretation, I briefly reconstruct the genesis of Peirce's notion of immediate object in his semiotic writings of the years 1904-1909 and defend the view that, according to Peirce, only propositions have immediate objects.
\end{abstract}

Keywords: Charles Peirce, Gottlob Frege, sense, reference, meaning, immediate object, dynamic object, sign, proposition, speculative grammar, classification of signs

This paper argues against the standard, "Fregean" interpretation of Peirce's distinction between the immediate and the dynamic object of a sign. In brief, according to such a view the dynamic object corresponds to the Fregean Bedeutung of the sign - the object denoted or referred to by the sign, while the immediate object corresponds to the Fregean Sinn - the way the sign presents, captures, or represents the dynamic object. The Fregean interpretation has been proposed explicitly and implicitly in classic and recent scholarship, and is largely considered correct or at least a good approximation to Peirce's philosophical intentions.

I will argue that the Fregean interpretation does not fit the use that Peirce makes of the immediate/dynamic object distinction in his experiments with the classification of signs in the years 1904-1906. It is a fact that the distinction in question emerges around 1904 in the context of the classifications. And it is a fact that with the notion of immediate object Peirce succeeds in establishing, besides the trichotomy of icon, index and symbol obtained with the dynamic object (or object tout court before 1904) a new and different trichotomy of signs, which would remain a relatively constant 
item in all his subsequent taxonomic attempts (1904-1909). This new trichotomy is into vague signs, singular signs, and general signs, that is, into particular, singular, and universal propositions. It follows that the division "according to the immediate object" that recurs in Peirce's speculative grammar (1904-1906) is a division of propositions according to their quantity. There is a sense in which only propositions and propositionlike signs have immediate objects.

Section 1 exposes the Fregean interpretation. Section 2 briefly reconstructs the genesis of Peirce's notion of immediate object in his semiotic writings of the years 1904-1908. Section 3 defends the view that, according to Peirce, only propositions have immediate objects. ${ }^{1}$

1. Gottlob Frege distinguished between the Bedeutung (reference) and the Sinn (sense) of a Zeichen (sign) in his celebrated 1892 essay "Über Sinn und Bedeutung". This distinction was foreshadowed in the Begriffsschrift, where he had spoken of a same content (Inhalt) being given by two different modes of determination (Bestimmungsweisen) (Frege 1879, $₫ 8$ ). Here is how he presents the distinction in the 1892 essay:

It is natural, now, to think of there being connected with a sign (name, combination of words, letter), besides that to which the sign refers, which may be called the reference (Bedeutung) of the sign, also what I should like to call the sense (Sinn) of the sign, wherein the mode of presentation is contained. (Frege 1960: 57)

The expressions " $3+4$ " and " $2+5$ " have the same denotation (Bedeutung) but express different senses (Sinne), that is, different ways of presenting the same number. In Frege's geometrical example, the expressions "the point of intersection of $a$ and $b$ " and "the point of intersection of $b$ and $c$ " have the same Bedeutung (the point o), while their Sinne differ. Likewise, in the famous astronomical example the Bedeutung of 'the evening star' and of 'the morning star' is the same (Venus), but their Sinne are different. The distinction is not restricted to proper names, but also embraces common nouns and sentences (1960: 62-65), the Bedeutung of a sentence being its truth-value. This distinction is a well-established one in contemporary philosophy of language. ${ }^{2}$

Now, the Peircean distinction between the immediate and the dynamic objects of a sign has often been taken to account for something similar to the Fregean distinction

1 The following abbreviations will be used for Peirce's works: CP, followed by volume and paragraph number, stands for Peirce 1931-1958; NEM, followed by volume and page number, for Peirce 1976; SS, followed by page number, for Peirce 1977; MS, followed by Robin catalogue number and, when available, page number, for the unpublished manuscripts in the Houghton Library of Harvard University, as cataloged in Robin 1967.

2 See e.g. Beaney 1996, Ch. 6; Macbeth 2005, Ch. 4. 
between Sinn and Bedeutung. A champion of the Fregean interpretation is Umberto Eco. Eco (1976: 1462) suggests that "the immediate object seems to be defined as the manner in which the sign circumscribes the way of looking at the object from the point of view of a given sign's focus (something similar to Frege's Sinn as opposed to Bedeutung)". In Lector in fabula (1979) Eco goes to great pains to disentangle and clarify several of Peirce's semiotic notions. According to him, ground, interpretant and meaning, although "different formal objects of different semiotic approaches and according to different points of view" (Eco 1979: 32), are in fact one and the same thing. The immediate object is similarly said to be the "meaning" of the sign: "signs only 'know' Immediate Objects, namely meanings" (Eco 1979: 44). For Eco, it is the notion of ground which serves to distinguish the dynamic from the immediate object of a sign; the immediate object "is the manner in which the Dynamic Object is focalized, this manner being nothing else than the ground or meaning" (Eco 1979: 31).

The Fregean interpretation of Peirce's distinction has recently been proposed explicitly by Gérard Deledalle: "According to Frege, a sign (Zeichen) 'stands for' (bedeutet) its objects in exactly the same way as the sign represents its object for Peirce. Moreover, it has for Frege as for Peirce, two objects: a dynamical or referential object (Bedeutung) and an immediate object or sense (Sinn)" (Deledalle 2000: 139). Also Atkin (2008: 72) speaks of an "obvious analogy" between Frege's Bedeutung/Sinn distinction and Peirce's dynamic/immediate object distinction: "Frege, for instance, takes a sign's Bedeutung to be the object for which it stands; similarly, for Peirce, the dynamic object is the real object signified by the sign"; Frege's Sinn and "the immediate object look like bedfellows. And indeed, many of the key theses that hold of Fregean Sense seem to hold of the Peircian Immediate Object" (Atkin 2008: 73).

An immediate corollary of the Fregean interpretation is that immediate objects are accumulative: "[ $t$ ]he form that we attribute to the Dynamic Object is continuously changed through the formulation of Immediate Objects and their constant redefinition by successive interpretants" (Eco 1984: 45); "one immediate object builds upon the next as a semiotic chain tends towards a final end" (Atkin 2008: 73). Since, according to this interpretation, the immediate object is one of the possible ways in which a sign "captures" (intensionally) the dynamic object, several immediate objects might correspond to the same dynamic object, none of which excludes the others. Let the historical G. W. Leibniz be the dynamic object. Then, the portrait of Leibniz made by Christoph Bernhard Francke, the statue of Leibniz in the University of Leipzig, and the image of Leibniz on a German postage stamp would be three different ways of representing the same dynamic object. Each represents the dynamic object differently, and, accordingly, has a different meaning: the portrait may be said to focus on the colour of the skin; the statue may be said to emphasize the proportions of Leibniz's body; the stamp may be said to capture the essence of Leibniz's eyes. Each of these 
aspects is (what Peirce has sometimes called) the ground of a particular representation of the dynamic object. Each of them is a partial and perspectival representation of the dynamic object. Immediate objects, Sinne, meanings, are therefore accumulative: to what the portrait represents we might add what the statue represents, and to this we might add what the stamp represents. The ideal sum of all these different, perspectival immediate objects would approximate the dynamic object, the historical Leibniz. I am sure that many conscious or unconscious supporters of the Fregean interpretation would substantially agree with this description of Peirce's position.

Now, a first, obvious objection to the Fregean interpretation is that for Frege a Zeichen may have a Sinn without having a Bedeutung; 'Odysseus' in "Odysseus was set ashore at Ithaca while sound asleep" has a Sinn (arguably, a definite description), but no Bedeutung (Frege 1960: 62-63). So for Frege "in grasping a sense, one is not certainly assured of a reference" (1960: 58). The sign may name a fictional character, one which has no existence but in the world of fiction or imagination; in this case, the sign has a sense, but no a reference. If the parallelism were consistent, we should likewise expect that for Peirce any proper name like Odysseus or Hamlet would have an immediate object, but no dynamic object. This, however, is by no means Peirce's position:

[...] the Dynamical, or Genuine Object. It is misleading to call it the real object, since it maybe unreal. (Logic Notebook, MS 339, 279r, 1906)

We must distinguish between the Immediate Object, - i.e. the Object as represented in the sign, - and the Real (no, because perhaps the Object is altogether fictive, I must choose a different term, therefore), say rather the Dynamical Object. (Peirce to James, CP 8.314, 1909)

Whether the object of a sign exists in the actual world or just in Shakespeare's world, Peirce would nonetheless speak of the dynamic, not of the immediate object of that sign. ${ }^{3}$ Whatever the universe of discourse, the object referred to or represented is the dynamic, not the immediate object. In Fregean terms, for Peirce all signs, even signs of non-existent objects, have a Bedeutung: 'Barack Obama' has a Bedeutung in the actual world, 'Hamlet' only in Shakespeare's world. This discrepancy alone is sufficient to undermine confidence in the Fregean interpretation.

In what is certainly the best book on Peirce's theory of signs we find a variant of the Fregean interpretation, which may be called the "stoic interpretation". According to Sextus, the Stoics claimed that in language "three things are linked together: what is signified ( $\tau \dot{o} \sigma \eta \mu \alpha \iota v o ́ \mu \varepsilon v o v$ ), that which signifies ( $(\dot{o} \sigma \eta \mu \alpha \tilde{v} v o v$ ), and the object

3 Bergman (2008: 105) agrees: "the dynamical object may be altogether unreal in the ordinary sense of the word". 


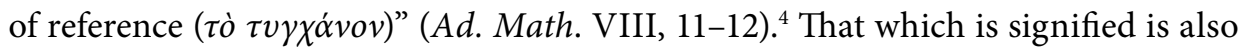
described as the "sayable" ( $\lambda \varepsilon \kappa \tau o ́ v)$. T. Short explicitly draws a parallel between the Stoics' $\lambda \varepsilon \kappa \tau o ́ v$ and Peirce's immediate object:

Peirce's distinction between a sign's immediate object and its dynamic object was more clear, more constant, and less original than were his divisions of interpretants. It goes back to the Stoic distinction [...] between the object as represented, or lektonthe immediate object - and the object as it exists independently of its representation the dynamic object. If I say, 'my mother', and my father says, 'my wife', the object of these two expressions is the same in herself but is represented differently as mother of the one and as wife of the other. You could apprehend the object as represented in either expression without knowing that it is the same person. (Short 2007: 179-180)

The evident problem with Short's stoic interpretation is that for the Stoics a complete $\lambda \varepsilon \kappa \tau o ́ v$ has a propositional size: "they [the Stoics] define the proposition as a complete $\lambda \varepsilon \kappa \tau o ́ v$ that is assertoric (i.e., true or false) in itself" (e.g., "Dion is walking", S. E., Pyrrh. Hyp. II, 104-106). But there are also incomplete $\lambda \varepsilon \kappa \tau \dot{\alpha}$, like predicates and the like (e.g., "is walking", cf. Diog. Laert. VII, 63). In Short's example, "my mother" and "my wife" would count as such incomplete or fragmentary $\lambda \varepsilon \kappa \tau \dot{\alpha}$, because neither expresses a complete sense capable of truth-value. This is true also for Frege: both concepts and sentences have a Sinn, although a concept has an unsaturated Sinn, while a sentence has a saturated Sinn. ${ }^{5}$

Those interested in the stoic interpretation should then inquire whether there is or should be a parallel distinction in Peirce between a complete and an incomplete immediate object of a sign, and whether such a distinction is used to account for the saturated/unsaturated contrast. Now, Peirce does use the chemical metaphor and speaks of complete and incomplete signs, ${ }^{6}$ that is, complete, saturated propositions and incomplete, unsaturated rhemes. But he never says, for instance, that propositions have a complete immediate object while rhemes have only an incomplete immediate objectas the stoic interpretation, if followed only a little further than Short actually does, inevitably suggests. The distinction proposition/rheme - upon which Peirce in fact put

4 On the Stoics' theory of language and doctrine of sign-inference see Manetti 1987, Ch. 6.

5 Cf. Gaskin 2008: 128-130. Benson Mates (1953: 19-21) has drawn an analogy between the Stoic concept of $\lambda \varepsilon \kappa \tau o ́ v$ and Frege's notion of Sinn.

6 "a sign may be complex; and the parts of a sign, though they are signs, may not possess all the essential characters of a more complete sign" (MS 7, 1, c. 1903); "the complete Representamen represents the Object, not only as the sign of which it is the copy does, but also independently and generally vaguely in a second Representamen" (R 478, variant draft of p. 43, 1903); "[i]n addition however to denoting objects every sign sufficiently complete signifies characters, or qualities" (NEM 4: 239, 1904); "a complete sign has or may have Parts which partake of the nature of their whole; but often in a truncated fashion” (MS 277, c. 1907; my emphasis, F. B.) 
much emphasis and which he obtains through the classification - is not obtained by a typology of immediate objects, but by the presence in the sign of an immediate object, as I will explain in Section 3. A different typology of immediate objects exists, and is indeed intended to distinguish not between propositions and rhemes, but among different kinds of proposition, as I will explain in Section 2.

The Fregean interpretation seems to manifest the following two defects: (1) Frege's Sinn/Bedeutung and Peirce's immediate/dynamic object distinctions do not match in the case of non-existing objects; (2) Peirce does not distinguish between complete and incomplete immediate objects, but between complete and incomplete signs. Both (1) and (2) are the result of pushing the Frege-Peirce analogy only little further; but both are only superficial manifestations of a presupposition that lies at the root of both the Fregean and the stoic interpretations: that the immediate object of a sign has something to do with the "meaning" of that sign, whatever "meaning" might mean in Peirce's vocabulary. This view is best expressed by Joseph Ransdell (2007): “The dynamical object is 'the thing itself,' transcending any given cognition though not beyond cognition generally, whereas the immediate object is the thing as immanent in semeiosis, the thing as it appears to be (is thought to be)". ${ }^{7}$ This assumption is also present in Eco's and Short's accounts. But as Frederik Stjernfelt (2014: 98) has persuasively argued, the immediate object has nothing to do with the meaning of the sign: "neither the Immediate Object nor the Dynamic Object is concerned with descriptive characters - this is left to the meaning categories. Both deal with the identity of reference". It is true that there are passages in which Peirce speaks of the representative ${ }^{8}$ and ideal ${ }^{9}$ nature of the immediate object. But he is on the other hand equally clear that the "meaning" or "descriptive content" of a sign resides in its interpretant, not in its object, be it dynamic or immediate. ${ }^{10}$ That the immediate object has a representative nature does not imply that it is to be taken for the meaning of the sign, whatever "meaning" is for Peirce. As he explains to Lady Welby,

7 Ransdell, Joseph 2007. "On the use and abuse of the immediate/dynamical object distinction”, Arisbe Eprint. (http://www.iupui.edu/ arisbe/menu/library/aboutcsp/ransdell/ useabuse.htm, accessed March 31, 2015.)

8 "Prolegomena", CP 4.536, 1906.

9 "This requaesitum I term the Object of the sign; - the immediate object, if it be the idea which the sign is built upon, the real object, if it be that real thing or circumstance upon which that idea is founded as on bed-rock" (MS 318, 1907). This passage has suggested to Helmut Pape (1990: 382) that the immediate object is "just the idea of an object to which the sign gives rise", which is almost literally the definition that Peirce gives of the interpretant of a sign. The sign "Hamlet was mad" is build on Hamlet as its subject, or at least on the idea that we have of Hamlet, for otherwise the sign would not functions as such; while the sign itself conveys the further idea of madness as applicable to the object, or to our idea of it.

10 "Harvard Lectures on Pragmatism", CP 5.165, 179, 1903; “Pragmatism”, MS 318, 14-15. 
signification is only one of the two chief functions of signs; as the elegant and correct John of Salisbury notices, in referring to "quod fere in omnium ore celebre est, aliud scilicet esse quod appellativa significant, et aliud esse quod nominant. Nominantur singularia, sed universalia significantur." (Metalogicus II. xx. I copy from the ed. of 1620.) (CP 8.378)

A sign both denotes and connotes, nominat et significat. It denotes its object and signifies its interpretant. It says something, and also indicates that of which it says what it says. It may be thought that the dynamic object corresponds to what the sign nominat, while the immediate object corresponds to what the sign significat. Mats Bergman (2008: 86) suggests something along these lines:

Peirce does acknowledge the fact that the utterer not only identifies and delimits the subject of discourse, but typically asserts something about that topic or at least presents it in a certain way; this aspect of saying something about something in some manner is conceptualized as the immediate object in distinction from the dynamical object that encompasses identification and demarcation.

I perfectly agree that Peirce acknowledges the fact that signs both denote and connote. But I disagree that the immediate object conceptualizes the connotative side of semiosis: both dynamic and immediate objects are on the denotative side. What follows outlines the main reasons I have found to support the view that the immediate object is that part of a sign that denotes the dynamic object.

2. The distinction between the immediate and the dynamic objects is a relatively late product of Peirce's semiotic enterprise. It seems to emerge in 1904. The nearest Peirce came to some such distinction before 1904 is in the first version of speculative grammar of the Syllabus (MS 478, 43-105), where Peirce "deduces" the bi-partite structure of the proposition (dicisign) from its Aristotelian definition as bearer of truth-value. Peirce distinguishes a primary object, the object represented, and a secondary object, the manner the sign is represented by its interpretant to represent the primary object. In the case of dicisigns, this manner is indexicality, so the dicisign is represented to be an index of its primary object, this indexical relation being the secondary object. The purpose of the "maze of these abstractions"1l is to show that since a dicisign is represented as an index, it must also have the bi-partite structure of an index, i.e. must have two parts. One of these parts stands for the (primary) object, the other for the dicisign itself; they are called subject and predicate of the dicisign, respectively. The primary object is the object external to the sign; the secondary object - Peirce says in MS 478 - is the way the sign is represented as representing its object.

11 CP 2.312. But see Stjernfelt 2014. 
All this disappears from the second version of speculative grammar that Peirce writes for the Syllabus ("Nomenclature and Divisions of Triadic Relations", MS 540) and which was probably intended to replace the former, had it ever reached print. In "Nomenclature and Divisions" there is no talk of more than one object. The three trichotomies come from the sign's relation to itself (qualisign, sinsign, qualisign), to its unique object (icon, index, symbol), and to its interpretant (rheme, dicisign, argument). ${ }^{12}$

Immediate objects first appear in a letter to Lady Welby from October 1904. Peirce here defines a sign as "an object which is in relation to its object on the one hand and to an interpretant on the other in such a way as to bring the interpretant into a relation to the object corresponding to its own relation to the object" (SS, 32). He then says that a sign has two objects and three interpretants, and that therefore signs are to be divided according to their own material qualities (qualisign, sinsign, legisign), according to their relations to their dynamic object (icon, index, symbol), to their immediate object (sign of quality, of an existent, or of a law), to their dynamic interpretant (submitted, urged, contemplated), to their immediate interpretant (thoughts, experiences, qualities of feelings) and to their significate interpretant (rheme, dicent, argument) (SS 32-35). This adds three further trichotomies to the initial three of the Syllabus, with a total of six (Fig. 1).

Peirce does nothing in the letter to explain what he means with the new trichotomy "sign of quality, existent, or law" relative to the immediate object. At least, this trichotomy does not correspond to the first one (qualisign, sinsign, legisign). It is not even much clearer what the new trichotomy of "interpretable in thoughts, interpretable in experiences, interpretable in qualities of feelings" relative to the immediate interpretant should mean. The trichotomy relative to the dynamic interpretant may have been intended to distinguish, e.g. the propositional content (proposition contemplated) from the act of assertion of that content (proposition urged). ${ }^{13}$ One thing is evident, however: Peirce's distinction between the dynamic and the immediate object is motivated by the classification of signs. The distinction has a grammatical or taxonomic purpose: it is needed to classify things. But we do not yet see what those things are which are thereby classified.

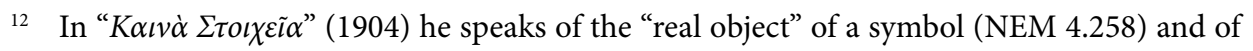
its "immediate interpretant" (NEM 4.261), but not of the immediate object.

13 This has been explained by Short (2007: 151-153). As Short notes, if we further specify the kind of urging by additional divisions (whether the sign or proposition is urged assertively, imperatively, interrogatively, etc.), we can arrive at a semiotic a priori classification of speech acts. This is what Peirce later does with the notion of 'pheme' (MS 295, 26, 1906). See also Bellucci 2014. 
"Nomenclature and Divisions of Triad Relations"

Syllabus MS540 Fall 1903

- the sign's relation to itself (qualisign, signsign, qualisign)

- to its object (icon, index, symbol)

- to its interpretant (rheme, dicisign, argument)
Peirce to L. Welby, Oct. 1904

SS pp. 32-35

- the sign's relation to itself (qualisign, signsign, qualisign)

- to its object dynamic (icon, index, symbol)

- to its immediate object (sign of quality, of an existent, or of a law)

- to its interpretant signified (rheme, dicisign, argument)

- to its dynamic interpretant (submitted, urged, contemplated)

- to its immediate interpretant (thoughts, experiences, qualities of feelings)

Figure 1. The three trichotomies of 1903 and the six of 1904.

Proceeding chronologically, some clues comes from a remark noted in the Logic Notebook in June 1905: "I use the terms immediate and direct, not according to their etymologies but so that to say that A is immediate to B means that it is present in B" (MS 339, 243v, 1 June 1905). "Immediate to" means "present in": to say that an object $\mathrm{A}$ is immediate to a sign $\mathrm{B}$ is to say that object $\mathrm{A}$ is present in sign $\mathrm{B}$. The immediate object is present in the sign, while the real or dynamic object is not present in the sign in the same sense, but "to be present in a sign" can mean nothing else than "to be part of a sign". Thus, the immediate object is part of the sign of which it is the immediate object. The real or dynamic object is not part of the sign in this sense.

A slightly later remark in the Notebook dispels the fog: a sign in relation to its immediate object is either vague, actual, or general.

A sign is a Priman which is Secundan to an Object and is Tertian in determining an Interpretant into Secundanity to that Object. It has two Objects, the immediate to which it is degenerately Secundan, the dynamic, to which it is genuinely Secundan [...] In its relation to its Immediate Object, it is a Vagosign if it represents that Object as possible, it is Actisign if it represents that Object as existent, it is General if it represents that Object as law. (MS 339, 247r, 1905 July 7) 
This is the classic division of propositions into particular, singular, and universal propositions. It is found in a logic book that Peirce knew very well, the Critique of Pure Reason. Kant's table of judgments, upon which he is to ground the table of categories by a metaphysical deduction, includes a division of judgments according to their Quantity: Universal, Particular, and Singular (KrV, A 70, B 95). Here is Peirce's dialogical and game-theoretical presentation of this trichotomy, without any appeal to the distinction between immediate and dynamic object being made:

If a sign is apt to represent many things, the option as to what single thing it shall be taken to represent may be reserved by the utterer of it, to whom it naturally belongs; in which case it may be said to be used vaguely, or not definitely. The utterer may, however, transfer this option to the interpreter; in which case the sign may be said to be used generally, or not individually. Obviously, the option cannot, in the same respect, at once lie with both parties. Hence, a sign cannot be at once vague and general in the same respect. It may, however, be both definite and individual; and in that case may be said to be used singularly. (MS 9, 2-3, c. 1903)

A sign which is used vaguely or not definitely is one in which the subject is existentially quantified, i.e. it is a particular proposition ("Some men are brave"); a sign which is used generally or not individually is one in which the subject is universally quantified, i.e. it is an universal proposition ("All men are brave"); a sign which is both definite (not vague) and individual (not general) is used singularly, i.e. is a singular proposition ("This man / Socrates is brave"). ${ }^{14}$ On October 8, 1905 Peirce again presents a similar division of Signs according to the Immediate Object: as Vague Signs, which represent the object as Indefinite; as Singular Signs, which represent the object as a Definite Individual; and as General Signs, which represent the object as Distributive general (MS 339, 252r). On October 10 he is most clear:

Signs are divisible according to their Objects. [...] According to their immediate objects. The immediate object is that object which the sign creates in representing it. 1. There are signs of each of which the immediate object is only a possible presentment of a dynamic object, a fragment of it, the rest being held in reserve, so that there is nothing in the immediate object to prevent contradictory attributes being predicated of it. Thus "A certain man" may turn out to be rich. He may turn out to be poor. Such a sign may be termed an indefinite sign.

2. There are signs of which the immediate object holds nothing in reserve, by supplying which the utterer can afterward limit it, nor allows any freedom of

14 Pietarinen (2006) has shown how such dialogical or game-like characterization of the theory of quantification explains the meaning of a quantifier as determined by the interaction between the Utterer and the Interpreter of the proposition. Cf. also CP 3.479. 
interpretation, the immediate object precisely denoting the dynamical object. Such a sign is called a Singular Sign, a term in the use of which a certain latitude must be allowed, however; or else there will be no occasion on which it can be applied. 3. There are signs of each of which the immediate object is represented as exchangeable for any existent within specified or understood limits. Such may be termed a distributive sign. (MS 339, 256r)

The same division of propositions into particular, universal, and singular according to their immediate object is presented in various other places, among which are the 1905 paper "The basis of pragmaticism" (MS 284, 54-64) and the 1906 National Academy of Sciences paper "On the system of existential graphs considered as an instrument for the investigation of logic" (MS 499; 499s, 10). From a "Provisional division of signs" recorded in the Logic Notebook and dated 1906 August 31 we learn that "according to the Form under which the Sign presents its Immediate Object" a sign may be an Indefinite, a Designation, or a General (MS 339, 285r). We know that in the 1906 "Prolegomena" Peirce writes that "we have to distinguish the Immediate Object, which is the Object as the Sign itself represents it, and whose Being is thus dependent upon the Representation of it in the Sign, from the Dynamical Object, which is the Reality which by some means contrives to determine the Sign to its Representation" (CP 4.536). However, here Peirce does not spell out the details of the trichotomies resulting from his divisions.

In fact Peirce's taxonomic ambitions of 1903-1906 are put to rest in the immediately following years, to be resumed only between 1908 and 1909 (cf. MS 339, 360v, 1909). In a long letter to Lady Welby from December 1908 we read:

The Mediate Object is the object outside the Sign; I call it the Dynamoid Object. The Sign must indicate it by a hint; and this hint, or its substance, is the Immediate Object. [...] If the Immediate Object is a "Possible," [...] I call the Sign a Descriptive; if the Immediate [Object] is an Occurrence, I call the Sign a Designative; and if the Immediate Object is a Necessitant, I call the Sign a Copulant; for in that case the Object has to be so identified by the Interpreter that the Sign may represent a necessitation. My name is certainly a temporary expedient. (SS 84)

In a variant draft Peirce had written: "it is necessary to distinguish the Immediate Object, or the Object as the Sign represents it, from the Dynamical Object, or really efficient but not immediately present Object" (CP 8.343), after which he had presented the trichotomy into Descriptives, Designatives, and Copulants (CP 8.350). The dynamic object is not "immediately present" in the sign, i.e. is not part of the sign. Still, there must be a part of the sign which indicates or represents the dynamic object. This part deputed to indicate the dynamic object is the immediate object of the sign, which is in fact immediately present in, i.e. a part of, the sign itself. Peirce here offers a different 
and admittedly obscure terminology for his trichotomy than the one presented in 1904-1906. That the substance of his division is identical is, however, apparent from what he says of the Copulant sign: it is the interpreter of the Copulant sign which has the right to identify the object of the sign - which evidently corresponds to the earlier game-theoretical characterization of the universal quantifier. If the 1908 Copulant sign corresponds to the 1905 General sign, or to some generalization of it, ${ }^{15}$ then it is reasonable to assume that Descriptives correspond to Vague signs and Designatives to Singular signs (Fig. 2). Given this identification, we may with confidence affirm that the trichotomy of signs according to their immediate objects, discovered in 1904, remains a relatively stable component of the subsequent classifications, and that the notion of immediate object is the instrument for the division of propositions according to what traditional logic calls their "quantity".

"sign of quality, existent, or law"

L. Welby, Oct. 1904

Vagosign, Actisign, General

MS 339, p. 247r, July 71905

Vague Signs, Singular Signs, General Signs

MS 339, p 252r, Oct. 81905

indefinite, singular, distributive sign

MS 339, p 256r, Oct. 101905

Descriptives, Designatives and Copulants

L. Welby, Dec. 1908, CP 8.350

Figure 2. The trichotomy "according to the immediate object" 1904-1908.

15 In fact in November 1909 Peirce writes in the Logic Notebook: "Looking over the book labelled in red 'The Prescott Book', and also this one, I find the entries in this book of 'Provisional Classification' of 1906 March 31 and of 1905 Oct 13 particularly important from my present (accidentally limited, no doubt) point of view". In both schemes the trichotomy according to the immediate object is into indefinite, singular, and general, so he is implying that he judges this division to be somehow correct (thanks to Ahti Pietarinen for drawing attention to this later remark). That by 1907-1908 Peirce might have generalized and perhaps modified his notion of the immediate object is not unlikely, and rather this would contribute to explaining why he is more inclined to talk of the "representative" and "ideal" nature of the immediate object in those years (thanks to Frederik Stjernfelt for discussing this point with me). But one thing is certain: the distinction must have a precise role in the classification, and in 1904-1906 this role is recognizably that of providing a typology of quantification. No account of Peirce's "immediate object" should neglect this fact. 
3. If this reconstruction, though certainly partial, is correct in substance, then I do not see why we should not accept the following statement concerning Peirce's theory of signs: only propositions and proposition-like signs have immediate objects. All signs have dynamic objects; but not all signs have a part of themselves deputed to represent those objects, that is, not all signs have an immediate object. Peirce is very clear that the immediate object has nothing to do with the meaning of the sign, but with its denotation. When he writes that the immediate object is "the object as represented by the sign", what he means is the object as "represented (indicated, denoted) in one part of the sign". So he writes to William James on March 14, 1909:

For instance, suppose I awake in the morning before my wife, and that afterwards
she wakes up and inquires, "What sort of a day is it?" This is a sign, whose Object, as
expressed, is the weather at that time, but whose Dynamical Object is the impression
which I have presumably derived from peeping between the window-curtains. [...]
I reply, let us suppose, "It is a stormy day". Here is another sign. Its Immediate Object
is the notion of the present weather so far as this is common to her mind and mine-
not the character of it, but the identity of it. The Dynamical Object is the identity of
the actual or Real meteorological conditions at the moment. (CP 8.314)

The dynamic object of the Peirce's reply "It is a stormy day" is the real meteorological condition. Its immediate object is the reference made within the sign to the dynamic object, the way in which the sign indicates that object. It is the subject "it", or any other means the sign has to make reference to the present subject of discourse, or to select it from the universe of discourse. A particular assertion contains an instruction as to how to make the selection, a universal contains a different instruction; they have different immediate objects. Immediate objects are means of reference. Anything that belongs or has any role in the determination of the reference of a sign, is part of its immediate object:

A man, tramping along a weary and solitary road, meets an individual of strange mien, who says, "There was a fire in Megara." If this should happen in the Middle United States, there might very likely be some village in the neighborhood called Megara. Or it may refer to one of the ancient cities of Megara, or to some romance. And the time is wholly indefinite. In short, nothing at all is conveyed, until the person addressed asks, "Where?" - "Oh about half a mile along there" pointing to whence he came. "And when?" "As I passed." Now an item of information has been conveyed, because it has been stated relatively to a well-understood common experience. (CSP to LW, SS, p. 197, March 9, 1906)

Immediate objects account for the intersubjectivity of reference. A sign functions as such if it identifies an object that is common to the utterer's and the interpreter's experiences. In Peirce's example of his wife asking about the weather, the present 
meteorological condition is the dynamic object of the sign; the reference to that present condition, in so far as the Peirces have in mind the same portion of the dynamic object and refer to it in conversation - and the sign must make some such reference in order to convey the information it professes to convey - that intersubjective reference is the immediate object of the sign. "The character of it", its being a stormy day (or in the example of Megara, there being a fire) is not part of the object, but part of the interpretant: is what the sign says of the present condition, after having identified it.

Now a sign which in addition to saying something also indicates that of which it says what it says, must have a propositional size; for this is exactly how Peirce defines a proposition, for example in this letter to Christine Ladd-Franklin:

Now a symbol may have such a relation to its object that it does not determine what the interpretant is to be. If it does determine that interpretant it is an argument. Its interpretant is its conclusion. If it does not do so, it still needs some application in an interpretant to give it any signification, but it does not specify what that interpretant or what that application is to be. In that case it may determine what its object is to be, \& not merely leave it to be whatever it may be. In that case it asseverates, that is, it is either true or false, and is called a proposition (CSP to CLF, MS L 237, 1901)

"A sign separately or independently indicating its object" is what Hilpinen (1992: 473) has aptly called the "standard definition" of a proposition, which is found, e.g., in the New List of 1867 (CP 1.559), in Baldwin's Dictionary (CP 2.357, 1901), in the Harvard Lectures of 1903 (CP 5.76, 5.139, 1903), in the Syllabus (MS 478, CP 2.311,

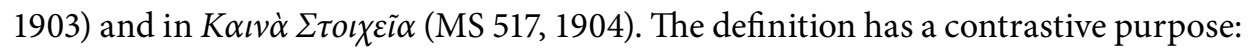
propositions differ form arguments in that the latter not only separately represent the object, but also separately represent the interpretant (the conclusion); but most importantly for our present purpose, propositions differ from predicates or rhemes, for a rheme does not separately represent its object, but merely leaves that object indefinite. To say that a sign separately represents its own object is to say that it has such a structure as to involve, as a separate part of it, a representation of that object. But as soon as a sign has such a minimal structure, i.e. as soon as it has a separate part of it deputed to represent the object, that sign is a proposition. In the post-1904 semiotic terminology, as soon as a sign has a part deputed to indicate the dynamic object, this part being called the immediate object of the sign, that sign is a proposition. ${ }^{16}$ Hilpinen's

16 The objection may be raised that Peirce's vague signs, general signs, etc. are predicates, e.g. "some man", "all men", etc., and not propositions, like "some man is brave", "all men are brave", etc. The reply is, though, that Peirce's own analysis of the proposition suggests distinct separation of the quantified (Hopkinsian) part from the predicative or rhematic (Boolean) part. 
standard definition may thus be reformulated: a proposition is a sign that has an immediate object.

An immediate consequence of this is that immediate objects are not accumulative; rather, they are mutually exclusive: a proposition is either particular or universal, but not both. On the contrary, the historical Leibniz has both the colour of the skin represented in the painting and the physique represented in the statue, these "immediate objects" being not mutually exclusive but rather accumulative. All the things that the different signs of Leibniz can communicate to us, are characters of Leibniz, and thus interpretants, not objects, of those signs. But in so far as those signs have a part deputed to indicate that of which they are signs (e.g., the painting has a legend, the statue an incision), they behave like propositions (typically, singular propositions: "Leibniz was such and such"). "Meanings" are in the above sense accumulative (when considered as characters), but it makes little or no sense to claim that denotation is accumulative in the same sense.

As noted in Section 1, following the Fregean and stoic interpretation of Peirce's distinction between the immediate and the dynamic objects would require us to treat the immediate object as Frege's Sinn and the Stoics' $\lambda \varepsilon \kappa \tau$ ó $v$ of a significant expression. In turn, since Frege's Sinn may be either saturated or unsaturated, and the Stoics' $\lambda \varepsilon \kappa \tau o ́ v$ either complete or incomplete, this would require us to look for a similar distinction in Peirce between complete and incomplete immediate objects. Now, it has emerged that the distinction that Peirce in fact makes is that between complete and incomplete signs, not between complete and incomplete objects of signs. He does distinguish between complete signs or propositions and incomplete signs or rhemes in terms of the immediate object: proposition-like signs are those that have an immediate object, while rheme-like signs are those that lack an immediate object. According to the Fregean interpretation, however, all signs have immediate objects (complete if they are propositions, incomplete if they are terms). According to my reconstruction, only propositions have immediate objects, and propositions different in quantity have different immediate objects (vague, singular, or general). The contrast is evident: if all signs are to have immediate objects, as the Fregean interpretation implies, then the 1904-1908 trichotomies "according to the immediate object" should be divisions of all signs. But not all signs have quantity, at least according to Peirce; rhemes, for example, have not. This seems to me an insurmountable difficulty for the Fregean interpretation.

I claim that my interpretation is supported by textual evidence, while the Fregean interpretation is not. In Section 2 I have reported the steps by which Peirce introduces the immediate/dynamic object distinction in the classification of signs. Although Peirce's own characterization of the distinction is obscure and sometimes even

Also, rhemes are classified according to a more characteristic parameter (valency; compare the schemes of MS 284, 1905, and MS 499s, 1906, with MS 339, 285r, 1906). 
confusing, the way he uses this distinction in his grammatical discussions, the apparent immediate purpose for which it is introduced, and the effects of its introduction for the classification of signs, can hardly leave any doubt that the notion of immediate object is intended to account for the dimension of reference within a quantificational theory of propositions. ${ }^{17}$

\section{References}

Atkin, Albert 2008. Peirce's final account of signs and the philosophy of language. Transactions of the Charles S. Peirce Society 44(1): 63-85.

Beaney, Michael 1996. Frege: Making Sense. London: Duckworth.

Bellucci, Francesco 2014. 'Logic, considered as Semeiotic': On Peirce's philosophy of logic. Transactions of the Charles S. Peirce Society 50(4): 523-547.

Bergman, Mats 2008. Peirce's Philosophy of Communication. London: Continuum.

Deledalle, Gérard 2000. Charles S. Peirce's Philosophy of Signs: Essays in Comparative Semiotics. Bloomington: Indiana University Press.

Eco, Umberto 1976. Peirce's notion of interpretant. MLN 91(6): 1457-1472.

- 1979. Lector in fabula. Milano: Bompiani.

- 1984. Semiotics and the Philosophy of Language. London: Macmillan.

Frege, Gottlob 1879. Begriffsschrift, eine der arithmetischen nachgebildete Formelsprache des reinen Denkens. Halle: Nebert.

- 1960. Philosophical Writings. (Geach, Peter T.; Black, Max, eds.) Oxford: Blackwell.

Gaskin, Richard 2008. The Unity of the Proposition. Oxford: Oxford University Press.

Hilpinen, Risto 1992. On Peirce's philosophical logic: Propositions and their objects. Transactions of the Charles S. Peirce Society 28: 467-488.

Kant, Immanuel 1781[1787]. Kritik der reinen Vernunft. Riga: Hartknoch. [KrV]

Macbeth, Danielle 2005. Frege's Logic. Cambridge: Harvard University Press.

Manetti, Giovanni 1987. Le teorie del segno nell'antichità classica. Milano: Bompiani.

Mates, Benson 1953. Stoic Logic. Berkeley: University of California Press.

Pape, Helmut 1990. Charles S. Peirce on objects of thought and representation. Noûs 24(3): 375-395.

Peirce, Charles Sanders 1931-1958. (Hartshorne, Charles; Weiss, Paul, eds. 1931-1935; Burks, Arthur W., ed. 1958.) The Collected Papers of Charles S. Peirce. Cambridge: Harvard University Press. [In-text references are to CP, followed by volume and paragraph numbers.]

- 1976. The New Elements of Mathematics by Charles S. Peirce. (4 vols., Eisele, Carolyn, ed.) The Hague: Mouton. [In-text references are to NEM]

17 Research supported by Estonian Research Council Project PUT 267: Diagrammatic Mind: Logical and Communicative Aspects of Iconicity; PI Ahti-Veikko Pietarinen. This paper was written during my stay at Centro Ricerche Porto Conte, Alghero, in February 2015; I wish to express my gratitude to Andrea Galante and Paolo De Vita for their support and friendship. Many thanks also to Helmut Pape, Ahti-Veikko Pietarinen, and Frederik Stjernfelt for important grammatical discussions. 
- 1977. Semiotic and Significs. The Correspondence between Charles S. Peirce and Victoria Lady Welby. (Hardwick, Charles S., ed.) Bloomington: Indiana University Press. [In-text reference are to SS].

Pietarinen, Ahti-Veikko 2006. Signs of Logic. Dordrecht: Springer.

Robin, Richard S. 1967. Annotated Catalogue of the Papers of Charles S. Peirce. Amherst: University of Massachusetts Press. [In-text references are to MS.]

Short, Thomas L. 2007. Peirce's Theory of Signs. Cambridge: Cambridge University Press. Stjernfelt, Frederik 2014. Natural Propositions. Boston: Docent Press.

\section{Изучая спекулятивную грамматику Пирса: Непосредственный объект знака}

Автор статьи критикует интерпретацию в духе Фреге пирсовского соотношения между динамическим и непосредственным объектами знака, где первый уподобляется фрегевскому Bedeutung, а второй - фрегевскому Sinn. После критического разбора автор реконструирует происхождение понятия непосредственного объекта в работах Пирса 1904-1909 годов и отстаивает точку зрения, что, согласно Пирсу, непосредственные объекты есть только у пропозиции.

\section{Peirce'i spekulatiivset grammatikat uurides: Märgi vahetu objekt}

Artiklis vaieldakse vastu sellele, mida nimetan Peirce'i poolt märgi vahetu ja dünaamilise objekti vahele tehtud eristuse fregelikuks tõlgendamiseks ja mille kohaselt on Peirce'i dünaamiline objekt sarnane Frege mõistega Bedeutung, vahetu objekt aga Frege mõistega Sinn. Pärast fregeliku tõlgenduse kriitilist käsitlemist rekonstrueerin lühidalt vahetu objekti mõiste väljakujunemise Peirce'i semiootika-alastes kirjutistes aastatel 1904-1909 ning kaitsen seisukohta, et Peirce’i järgi on vahetud objektid üksnes propositsioonidel. 


\title{
COMMENT
}

\author{
Helmut Pape $e^{18}$
}

Perhaps the most problematic feature of the paper by Francesco Bellucci is that the author, although he attacks the "Fregean interpretation" of the immediate object and the distinction between sense and reference, sticks to the strict divide of conceptual functions which Frege's distinction implies. That is to say, he does not ask whether this pair of concepts is adequate to capture Peirce's notion of pragmatic access conditions for the "unexpressed" objects of a sign. However, Peirce's concept of an immediate object is designed to capture the cognitive paths and conditions by which we are able to access and grasp those feature which determine the correct interpretation of signs. Even earlier, before introducing the immediate/dynamical distinction in 1903, and developing it explicitly in MS 318 in 1908, Peirce argued that cognitive access to "what we talk" about depends on the way how causal cognitive processes are related to language:

It would, certainly, in one sense be extravagant to say that we can never tell what we are talking about; yet, in another sense, it is quite true. The meanings of words ordinarily depend upon our tendencies to weld together qualities and our aptitudes to see resemblances, or, to use the received phrase, upon associations by similarity; while experience is bound together, and only recognisable, by forces acting upon us, or, to use an even worse chosen technical term, by means of associations by contiguity. (CP 3.419, 1895)

The author argues convincingly for the view that only assertions may have immediate objects. His reasoning sets out from the somewhat general but correct claim that "both dynamic and immediate objects are on the denotative side" of signs. The thesis of the author about what immediate objects are - which he did not explicitly state - is that they can be characterized by quantifiers. This surely gives us a partial, formal feature of immediate objects - but only of them and not of the dynamical object. Then why does Peirce stress, time and again, that in the case of the immediate object the equality of properties is decisive, whereas only in the case of the dynamical objects are we concerned with identity? A crucial question therefore is what function does the equality feature of immediate objects have. What does it contribute to the "denotative side" of signs in the semiotic relation? Why do we need immediate objects at all, if identity and therefore quantification are related to the dynamical object? These questions and the difficulties should be discussed with the notion of an object in general in Peirce's semiotics as a background. For Peirce points out that 'object' is a complex concept:

[t]hat the common use of the word "object" to mean a thing, is altogether incorrect. The noun objectum came into use in the XIIIth century, as a term of psychology. It means primarily that creation of the mind in its reaction with a more or less real something, which creation becomes that upon which cognition is directed; and secondarily, an object is that upon which an exertion acts; also that which a purpose seeks to bring about; also, that which is coupled with something else in a relation, and

18 Author's address: Universität Bamberg, An der Universität 2, D-96047 Bamberg, Germany; e-mail: helmut_pape@web.de. 
more especially is represented as so coupled; also, that to which any sign corresponds. (MS 693A, 33, 1904)

However, the paper does not address any of these issues. In fact, the author seems to imply that any concept of an object must be understood as to be directly and extensionally referential, excluding any contributory function of how the object is to be cognitively determined. The paper does not address any of those features that Peirce connected with the relation between a sign and its pragmatic, that is to say perceptual/experiential factors, that determine how objects are accessed. For instance, the objects to which cognition is directed and to which a sign corresponds are of course related to one another. What about the hypothesis that the notion of the immediate object was designed by Peirce to capture this feature of semiotic cognition? To see how close the relation between semiotic cognition and the immediate object was for Peirce, let us look at a passage in which Peirce explains his immediate/dynamical object distinction:

Take for example, the sentence the Sun is blue. "Its Objects are "the Sun" and "blueness." If by "blueness" be meant the Immediate Object, which is the quality of the sensation, it can only be known by Feeling. But if it means that "Real," existential condition, which causes the emitted light to have short mean wave-length, Langley has already proved that the proposition is true. So the "Sun" may mean the occasion of sundry sensations, and so is Immediate Object, or it may mean our usual interpretation of such sensations in terms of place, of mass, etc., when it is the Dynamical Object. It is true of both Immediate and Dynamical Object that acquaintance cannot be given by a Picture or a Description, nor by any other sign which has the Sun for its Object. (CP 8.183)

In Peirce's most extensive and carefully argued text on the object of a sign in MS 318 one of his pragmatic theses is that the object is unexpressed by the sign - "taken by itself". Of course, this pragmatic thesis holds for both the immediate and the dynamical object. If you look at the way the immediate/dynamical object distinction varies in CP 8.183 it seems to be obvious that the cognitive and causal factors in the situation of utterance may be addressed in different ways, each way giving rise to different pragmatic paths and conditions of interpreting a sentence like "The sun is blue" correctly. This shows that the immediate/dynamical distinction is a pragmatic, and that is to a rhetorical one.

The immediate/dynamical object distinction plays a pragmatic role and is not a distinction restricted to speculative grammar. The author does not consider that all the examples he gives and the analysis of immediate objects in terms of quantificational burdens of proof distributed between the author and the interpreter of an assertion assigns a rhetorical function to immediate objects. In the case of proper names, Pietarinen 2010 has already shown that Peirce did not believe in Fregean reference that is determined by sense. However, the view that objects are rather pragmatically determined and differentiated by those causal and equality conditions is implied by the passage from CP 3.419 quoted above: perceptions, associations of ideas act as causal and rhetorical conditions. They bring it about that for us objects may "immediately" become part and parcel of dialogical sign processes, for only if my immediate object "sun" is the same as yours do we talk about the same issue. This, by the way, also explains why all of Peirce's sign definitions insist that the object determines the interpretant. 
To sum up, I think the author correctly stresses that "immediate object" does not conceptualize sense or connotation. However, he ignores the pragmatic, that is, nonconnotative, causal role which feelings, perceptions, associations and "ideas" have and which make up the pragmatic dimension of their practical, rhetorical role. This causal, path-opening role of ideas, feelings, etc. belongs to the very core of the semantic thought of Peirce who arrived at semantics via the pragmatic, the rhetorical. The concept of an immediate object is part and parcel of a family of semantic-pragmatic concepts related to the notion of the universe of discourse. This concept, adapted by Peirce from George Boole, is used e.g. in An Investigation of the Laws of Thought. For Boole, to have the same universe of discourse means that people agree in their thoughts or their "intercourse with others" (Boole 1854: 53) on the sort of objects they talk about; we are able to determine a common universe of discourse only because we engage in a rhetorical, selective activity using sensual or associative ideas or properties selectively. When we limit the field of discourse, he argued, "the operation which we really perform is one of selection according to a prescribed principle or idea" (Boole 1854: 43). Boole, like Peirce, was not interested in the psychological side of processes that we undergo when we perform this task. Rather, he insists that e.g. in using terms "to select mentally from the class of men all those who possess the further quality 'good"', we perform a kind of operation logically different from that of ascribing predicates to class members. The selective use of properties requires attention and imagination rather than rational judgment about propositions. Not only Peirce's use of 'universe of discourse', but his stress on common experience has its roots in Boole's rhetorical method. For Boole (1854: 44) points out: "Every name, every term of description that we employ, directs him who we address to the performance of a certain mental operation of that subject. And thus thought is communicated." So it is obvious that Peirce's use of 'universe of discourse' requires the semantical role common experience and subliminal perception. And this also constitutes the cognitive conditions for various immediate objects which therefore goes back to Boole too. The notion of an immediate object has its roots right here: for what can be more immediate - Peirce defines the immediate as being without a boundary - than an object determined by cognitive processes? which pragmatically select relative to a sign and which thereby force attention to some object without involving any conscious involvement? ${ }^{19}$

\section{References}

Boole, George 1854. An Investigation of the Laws of Thought on Which are Founded the Mathematical Theories of Logic and Probabilities. London: Walton and Maberly.

Peirce, Charles Sanders 1931-1958. (Hartshorne, Charles; Weiss, Paul, eds. 1931-1935; Burks, Arthur W., ed. 1958.) The Collected Papers of Charles S. Peirce. Cambridge: Harvard University Press. [In-text references are to CP, followed by volume and paragraph numbers.] Pietarinen, Ahti-Veikko 2010. Peirce's pragmatic theory of proper names. Transactions of the Charles S. Peirce Society 46: 341-363.

Robin, Richard S. 1967. Annotated Catalogue of the Papers of Charles S. Peirce. Amherst: University of Massachusetts Press. [In-text references are to MS.]

19 This comment was written during my stay as visiting scholar at the Cluster of Excellence 264 TOPOI (The Formation and Transformation of Space and Knowledge in Ancient Civilisations) at Humboldt-Universität zu Berlin. 